\title{
THE
}

\section{Large-Scale SST Variability in the Western North Atlantic Subtropical Convergence Zone during FASINEX. Part II: Upper Ocean Heat Balance and Frontogenesis}

George R. Halliwell Jr.

University of Rhode Island

Peter C. Cornillon

University of Rhode Island, pcornillon@uri.edu

Follow this and additional works at: https://digitalcommons.uri.edu/gsofacpubs

\section{Citation/Publisher Attribution}

Halliwell, G. R., \& Cornillon, P. (1990). Large-Scale SST Variability in the Western North Atlantic Subtropical Convergence Zone during FASINEX. Part II: Upper Ocean Heat Balance and Frontogenesis. J. Phys. Oceanogr., 20(2), 223-234. doi: 10.1175/1520-0485(1990)0202.0.CO;2

Available at: https://doi.org/10.1175/1520-0485(1990)020<0223:LSSVIT>2.0.C0;2

This Article is brought to you for free and open access by the Graduate School of Oceanography at DigitalCommons@URI. It has been accepted for inclusion in Graduate School of Oceanography Faculty Publications by an authorized administrator of DigitalCommons@URI. For more information, please contact digitalcommons-group@uri.edu. 


\title{
Large-Scale SST Variability in the Western North Atlantic Subtropical Convergence Zone during FASINEX. Part II: Upper Ocean Heat Balance and Frontogenesis*
}

\author{
George R. Halliwell, JR. AND Peter Cornillon \\ Graduate School of Oceanography, University of Rhode Island, Narragansett, Rhode Island
}

(Manuscript received 20 July 1988, in final form 18 August 1989)

ABSTRACT

\begin{abstract}
We analyzed the influence of wind-driven horizontal heat advection on the large-scale [O $(1000) \mathrm{km}$ wavelength ] variability of both the upper-ocean mixed-layer heat content and the subtropical frontal zone (SFZ) within an $11^{\circ}$ by $10^{\circ}$ domain in the western North Atlantic Ocean during FASINEX (January through June 1986). By estimating heat advection due to both Ekman transport and interior geostrophic (Sverdrup minus Ekman) transport from a slab mixed layer heat balance equation using satellite-derived sea surface temperature $\left(T_{s}\right)$ and wind analysis maps, it was found that these processes could not account for the observed variability in either heat content or the SFZ. The annual cycle of surface vertical heat flux had the dominant influence on the heat content. Even when the average heat balance was analyzed during a 4-month time interval when the net influence of the annual cycle was nearly zero (mid-January to mid-May 1986), westward-propagating $T_{s}$ spatial anomaly features with peak-to-peak scales of several hundred kilometers apparently had the dominant influence on heat content. The influence of Ekman transport appeared to become marginally detectable only when terms in the heat equation were zonally averaged across the entire analysis domain, apparently reducing the influence of the propagating anomaly features. Ekman transport did act to maintain the SFZ during the 4month interval, and thus may have been ultimately responsible for its existence, but the large-amplitude variability in heat content and the SFZ driven by other processes made this impossible to prove conclusively in the FASINEX region.
\end{abstract}

\section{Introduction}

A major objective of the large-scale component of the Frontal Air-Sea Interaction Experiment (FASINEX) (Stage and Weller 1985, 1986), which was conducted in the western North Atlantic subtropical convergence zone (STCZ), was to determine the processes active at large scales that generate the strong oceanic subtropical fronts observed there. In this paper, we describe our attempts to quantify the influence of winddriven horizontal heat advection on the large-scale $[O(1000) \mathrm{km}$ wavelength] variability of sea surface temperature $\left(T_{s}\right)$, and of the subtropical frontal zone (SFZ), in the FASINEX region during the experiment (January through June 1986). The SFZ was evident in smoothed $T_{s}$ maps as a predominantly zonally oriented band up to $3^{\circ}$ latitude wide where gradients were at least three times larger in magnitude than the climatological mean (Halliwell and Cornillon 1990, henceforth referred to as Part I). Since we focus exclu-

\footnotetext{
* FASINEX contribution no. 61.
}

Corresponding author address: Dr. George R. Halliwell, Graduate School of Oceanography, University of Rhode Island, Narragansett, RI 02882 sively on large scales, we do not consider the variability of individual fronts contained within the SFZ, across which $T_{s}$ can change by up to $3^{\circ} \mathrm{C}$ within $10 \mathrm{~km}$ (e.g. Voorhis 1969). These fronts are being extensively studied by other investigators as part of FASINEX (e.g. Pollard 1986; Böhm 1988).

Since the STCZ is the zone separating the westerlies to the north from the trade winds to the south in the Northern Hemisphere, the meridional convergence of wind-driven Ekman transport within it is assumed to be an important large-scale mechanism for generating the SFZ. (For simplicity, we will henceforth refer to wind-driven horizontal heat advection as Ekman advection, and to the meridional convergence of Ekman transport as Ekman convergence.) Models by deSzoeke (1980), Welander (1981), and Cushman-Roisin (1981) illustrate how Ekman advection can generate subtropical fronts. Observations of the subtropical front in the North Pacific Ocean (Roden 1975, 1980, 1981; Roden and Paskausky 1978) document the tendency for either the SFZ or individual subtropical fronts to be located near the latitude where Ekman convergence produces the strongest frontogenesis by either employing case studies or using seasonal mean data.

However, recent evidence has indicated that other mechanisms may produce frontogenesis at large scales. Cushman-Roisin (1984) and deRuijter (1983a) de- 
scribe models in which horizontal gradients of vertical heat fluxes produce frontogenesis in the absence of Ekman advection. As expected, the numerical model of Takeuchi (1984) generated a SFZ when it was driven by a wind stress distribution that produced meridional Ekman convergence within the STCZ. Surprisingly, the model also generated a SFZ when it was driven by a wind stress distribution that produced zonal Ekman convergence. Since the Ekman transport was essentially tangent to the $T_{s}$ isotherms in the latter case, other (unknown) processes must have produced this frontogenesis. It is also well known that mesoscale and submesoscale eddies strongly affect the variability of subtropical fronts at $O(100) \mathrm{km}$ and $O(10) \mathrm{km}$, respectively (e.g., Voorhis et al. 1976; Voorhis and Bruce 1982). However, the degree to which eddies influence $T_{s}$ and fronts at wavelengths of $\mathrm{O}(1000) \mathrm{km}$ is poorly known. Although existing evidence does suggest that Ekman advection plays a significant role in generating subtropical fronts, its importance relative to other processes, and how this importance depends on wavenumber and frequency, has yet to be quantified.

Although data limitations did not allow us to thoroughly answer these questions here, we are at least able to crudely analyze the influence of wind-driven horizontal heat advection on the large-scale variability of $T_{s}$ and the SFZ observed during FASINEX. To do this, we estimate and compare terms of a heat balance equation for an upper-ocean slab mixed layer, focusing primarily on the average heat balance during the FASINEX "winter" season (mid-January through midMay 1986, henceforth referred to as the 4-month in- terval). We analyze the influence of horizontal heat advection caused by both Ekman transport and interior geostrophic (Sverdrup minus Ekman) meridional transport. Our primary goal is to characterize the influence of Ekman advection in the FASINEX region to help answer the existing questions about its importance. Interior geostrophic transport is also considered since it can potentially advect the same order of magnitude of heat in the winter mixed layer as Ekman transport.

\section{Data}

The available data includes 5-day $T_{s}$ maps from 610 January through 25-29 June 1986 derived from NOAA-7 and NOAA-9 AVHRR/2 infrared images, along with wind stress maps calculated from Fleet $\mathrm{Nu}$ merical Oceanography Center (FNOC) wind analyses and then averaged over these same 5-day intervals. The $T_{s}$ maps were derived from 5-day composite images by binning all $T_{s}$ estimates not influenced by clouds into $0.25^{\circ}$ latitude by $0.25^{\circ}$ longitude boxes, then averaging these estimates within each box. FNOC wind analyses were obtained on a grid with $2.5^{\circ}$ resolution in both latitude and longitude. The $T_{s}$ and FNOC grids are shown in Fig. 1, along with the locations of FASINEX moorings (Pennington et al. 1988). We refer the reader to Part I for a description of the dataset and a discussion of the data processing that was performed. A quality evaluation of the dataset (Part I) indicated that it should represent large-scale variability reasonably well.

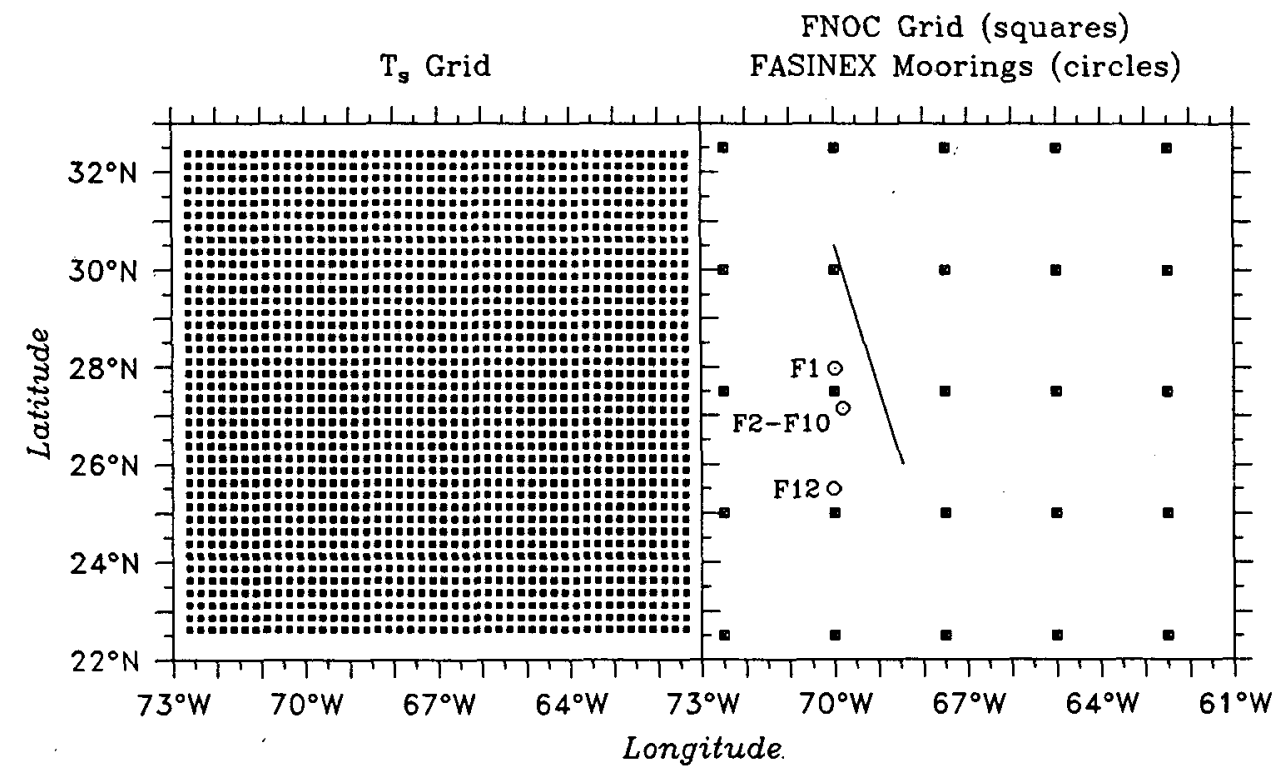

FIG. 1. Grid points used for the five-day $T_{s}$ maps (left) and grid points of the FNOC wind analyses (squares, right), along with the location of FASINEX moorings (circles, right). The straight line in the right panel is the FASINEX ship-of-opportunity track. 
Since the analyses performed in this paper required the calculation of second and third spatial derivatives of $T_{s}$, spatial smoothing was required to sufficiently minimize the smaller-scale variability contained in these fields (e.g., Part I, Figs. 13 and 14). We spatially smoothed the 5-day $T_{s}$ maps using a $9 \times 9$ point $\left(2^{\circ}\right.$ $\times 2^{\circ}$ ), two-dimensional Hanning window. A truncated smoothing window was used near the boundaries of the domain to retain as much spatial information as possible. We evaluated the effects of this smoothing by estimating and comparing zonal wavenumber autospectra from both a smoothed and unsmoothed 5-day $T_{s}$ map. The smoothing removes most of the $T_{s}$ variance with wavelengths $<200-300 \mathrm{~km}$ (Table 1).

\section{Heat balance}

\section{a. Equations}

The heat balance for a slab mixed layer of constant thickness $h$ separated from the ocean interior by a layer of thickness $\epsilon \ll h$, within which the velocity and temperature $\vec{v}_{m}(x, y, t)$ and $T_{m}(x, y, t)$ are assumed to be independent of $z$, is given by (e.g., deRuijter 1983b):

$$
\begin{aligned}
\rho_{0} c h T_{m t}= & -\rho_{0} \operatorname{ch}\left(\vec{v}_{m} \cdot \nabla T_{m}\right)-\rho_{0} \operatorname{ch}\left(\left\langle u^{\prime} T^{\prime}\right\rangle_{m x}\right. \\
& \left.+\left\langle v^{\prime} T^{\prime}\right\rangle_{m y}\right)-Q_{s}+Q_{h}-\rho_{0} c\left\langle w^{\prime} T^{\prime}\right\rangle_{s} \\
& -\rho_{0} c w_{e}\left(T_{m}-T_{i}\right) .
\end{aligned}
$$

The subscripts $x, y, z$, and $t$ denote partial differentiation; the subscripts $s, h$, and $i$ denote quantities evaluated at $z=0, z=-h$, and $z=-(h+\epsilon)$, respectively; $\rho_{0}$ is the density; $c$ is the specific heat; $\nabla$ is the horizontal gradient operator; angle brackets denote time averaging; primes denote turbulent fluctuations; $Q_{s}$ and $Q_{h}$ are vertical heat fluxes due to shortwave radiation; and $w_{e}$ is the vertical entrainment velocity at the base of the mixed layer. The time rate of change of mixedlayer heat content per unit area in this model is influenced by horizontal heat advection, horizontal turbulent heat diffusion, vertical fluxes of solar radiation at the surface and at the base of the mixed layer, and the contribution of other vertical heat fluxes at the sur-

TABLE 1. Ratio of zonal wavenumber autospectrum estimates calculated from one of the 5-day $T_{s}$ maps smoothed using a twodimensional $9 \times 9$ Hanning window to estimates calculated from the unsmoothed $T_{s}$ map for the same 5-day interval. Autospectrum estimates were calculated at each latitude, band-averaged over zonal wavenumber at each latitude, then averaged over latitude.

\begin{tabular}{cc}
\hline Wavelength $(\mathrm{km})$ & Ratio \\
\hline 568 & 0.84 \\
227 & 0.39 \\
142 & 0.37 \\
103 & 0.16 \\
81 & 0.01 \\
67 & 0.00 \\
\hline
\end{tabular}

face (sensible, latent, and longwave radiation) and at the base of the mixed layer.

We assume that the large-scale wind-driven horizontal current velocity in the mixed layer equals the vertically-averaged Ekman velocity $\left(\vec{v}_{E}\right)$ plus the vertically averaged meridional component of interior geostrophic (Sverdrup minus Ekman) velocity $\left(v_{i}\right)$ :

$$
\vec{v}_{E}=\frac{1}{\rho_{0} f h} \vec{\tau} \times \mathbf{k}
$$

and

$$
v_{i}=\frac{1}{\rho_{0} \beta H} \mathbf{k} \cdot(\nabla \times \vec{\tau})+\frac{1}{\rho_{0} f H} \tau^{(x)} .
$$

We have assumed that the wind-driven interior transport is confined to the upper ocean above a constant depth $H$, and hence we neglect topography.

Two potentially significant decay processes for largescale variability in heat content are the horizontal diffusive effects of mesoscale and submesoscale eddies (assuming that they act to reduce, not enhance, largescale $T_{s}$ gradients), and the tendency of the very-largescale [wavelengths of $O(10000) \mathrm{km}$ ] pattern of surface vertical heat fluxes to smooth out large-scale spatial $T_{s}$ perturbations. Diffusive effects can be modeled by the term $\rho_{0} c k \nabla^{2} T_{\mathrm{s}}$, where $k$ is the diffusion coefficient (assumed constant). The net effect of surface vertical heat fluxes can be modeled by a term proportional to ( $T_{s}$ $-T_{a}$ ), where $T_{a}$ is an effective equilibrium atmospheric temperature (Haney 1971) that is assumed to be dominated by very large space scales. Since we wanted to represent the decay of $T_{s}$ variability in some manner in our analyses, we included the diffusion term in the heat balance. The surface flux term was not included because it turned out to be very well correlated spatially with the diffusion term within the analysis domain if $T_{a}$ was represented as a linear function of latitude. No matter which decay term was included, the results of our analyses were similar.

If we introduce a remainder term $Q_{R}$ to represent all processes not explicitly modeled, (1) becomes

$$
\begin{array}{r}
\rho_{0} \operatorname{ch} T_{s t}=-\frac{c}{f} \mathbf{k} \cdot\left(\nabla T_{s} \times \vec{\tau}\right)-c \frac{h}{H}\left[\frac{1}{\beta} \mathbf{k} \cdot(\nabla \times \vec{\tau})\right. \\
\left.+\frac{1}{f} \tau^{(x)}\right] T_{s y}+\rho_{0} \operatorname{chk} \nabla^{2} T_{s}+Q_{R}
\end{array}
$$

where we have assumed that $T_{m}=T_{s}$. To determine how these processes influence frontogenesis, we first take the gradient of (4):

$$
\begin{aligned}
\rho_{0} \operatorname{ch}\left(\nabla T_{s}\right)_{t} & =-\frac{c}{f} \nabla\left[\mathbf{k} \cdot\left(\nabla T_{s} \times \vec{\tau}\right)\right] \\
-c \frac{h}{H} \nabla\left\{\left[\frac{1}{\beta} \mathbf{k} \cdot(\nabla \times \vec{\tau})+\frac{1}{f} \tau^{(x)}\right] T_{s y}\right\} & +\rho_{0} \operatorname{chk} \nabla\left(\nabla^{2} T_{s}\right)+\nabla Q_{R} .
\end{aligned}
$$


We then take the dot product between $\nabla T_{s}$ and (5) and divide by $\rho_{0} c h$ to obtain

$$
\begin{aligned}
& \left(\frac{\left|\nabla T_{s}\right|^{2}}{2}\right)_{t}=-\frac{1}{\rho_{0} f h} \nabla T_{s} \cdot \nabla\left[\mathbf{k} \cdot\left(\nabla T_{s} \times \vec{\tau}\right)\right] \\
& -\frac{1}{\rho_{0} H} \nabla T_{s} \cdot \nabla\left\{\left[\frac{1}{\beta} \mathbf{k} \cdot(\nabla \times \vec{\tau})+\frac{1}{f} \tau^{(x)}\right] T_{s y}\right\} \\
& +k \nabla T_{s} \cdot \nabla\left(\nabla^{2} T_{s}\right)+\frac{1}{\rho_{0} c h} \nabla T_{s} \cdot \nabla Q_{R} .
\end{aligned}
$$

Since frontogenesis (frontolysis) is occurring where the scalar quantity $\left|\nabla T_{s}\right|^{2}$ is increasing (decreasing), we refer to (6) as the frontogenesis equation.

\section{b. Problems and limitations}

Wind-driven horizontal heat flux is an order of magnitude smaller than some other components of the total heat flux, such as shortwave solar radiation. Consequently, $Q_{R}$ can be an order of magnitude larger than the wind-driven advection terms in (4). In an attempt to minimize this problem, we focus primarily on the temporally averaged heat balance during the 4-month time interval (mid-January to mid-May) in our subsequent analyses. The spatially averaged value of $T_{s}$ within the analysis domain at the end of the 4-month interval is nearly identical to the value at the beginning, increasing by only $0.17^{\circ} \mathrm{C}$. Because of this, the time derivative term of $(4)$ is the same order of magnitude as the combined contribution of the Ekman and interior advection terms when these terms are all averaged over the 4-month interval. Consequently, the net contribution of all other processes to this averaged heat balance cannot exceed the contribution of wind-driven advection, which increases our chance of detecting the response to this advection.

We must also consider how accurately we can estimate the influence of wind-driven horizontal heat advection considering the stringent assumptions required to derive those terms in (4). Estimates of the largescale pattern of Ekman advection in a slab mixed layer made using wind analyses or winds derived from weather charts have been used successfully in upperocean heat budget studies (e.g., Paduan and deSzoeke 1986), and in at least marginally detecting the response of the North Pacific subtropical front or frontal zone to Ekman heat advection (Roden and Paskausky 1978; Roden 1980). However, the validity of the Sverdrup balance in the North Atlantic has not been proven (Wunsch and Roemmich 1985). Sverdrup (1947) assumed that vertical velocity was driven by Ekman pumping only, and that a depth $H$ existed at which the vertical velocity was zero, thus confining the resulting transport above this depth and insulating it from the bottom. In reality, thermohaline and eddy-driven currents in the presence of topographic relief can produce vertical velocities that equal or exceed vertical velocities driven by Ekman pumping (Wunsch and Roemmich 1985). Roemmich and Wunsch (1985) also show that the influence of the Gulf Stream recirculation, where the Sverdrup balance is not expected to hold based on scaling arguments, may extend eastward across the entire analysis domain at $24^{\circ} \mathrm{N}$. In contrast, a time-dependent Sverdrup balance has been detected in two studies. Niiler and Koblinsky ( 1985 ) found that interior currents at $42^{\circ} \mathrm{N}$ in the northeast Pacific Ocean are coherent with wind stress curl at periods between 10 and 100 days in a manner consistent with a local, timedependent Sverdrup balance. Brink (1988) detected a surface-intensified response of currents to wind stress curl in the FASINEX area, but it was only partly consistent with a local Sverdrup balance since some of the variability was nonlocally forced to the east of this area. We do not consider nonlocal forcing in the present study. Despite these questions about the validity of the Sverdrup balance, we included the interior advection term in (4) just to test its validity in the FASINEX region since it can potentially be the same order of magnitude as the Ekman advection term assuming that $H \approx 1000 \mathrm{~m}$.

We do not expect the assumption of constant $h$ to cause drastic problems in our analyses. This contention is supported by the study of Roden and Paskausky (1978) who successfully used historical estimates of the mean values of $h$ as a function of latitude in the Pacific Ocean, instead of measured values of $h$, to detect the effects of Ekman advection on subtropical fronts. Using meridionally-smoothed XBT temperatures from ship-of-opportunity cross-sections (Fig. 1) run between $26^{\circ}$ and $30.5^{\circ} \mathrm{N}$ near $70^{\circ} \mathrm{W}$ (Evans et al. 1986; Halliwell 1990), $h$ was estimated to average $71.3 \mathrm{~m}$ with a rms amplitude of $13.0 \mathrm{~m}$ (Table 2).

TABLE 2. Estimates of the depth $h$ of the mixed layer base obtained from three ship-of-opportunity XBT cross-sections (see Fig. 1) during early 1986 , with $h$ defined as the depth where the temperature exceeds the mixed-layer temperature by $0.25^{\circ} \mathrm{C}$. The temperature field was first smoothed to remove variability with meridional scales $<100$ $200 \mathrm{~km}$, so smaller-scale variability of $h$ has been effectively filtered out. A detailed description of this data set is presented in Halliwell (1989). For these 27 estimates of $h$, the mean is $71.3 \mathrm{~m}$ and the rms amplitude is $13.0 \mathrm{~m}$.

\begin{tabular}{lccc}
\hline \hline & \multicolumn{3}{c}{ Depth estimates } \\
\cline { 2 - 4 } $\begin{array}{l}\text { Latitude } \\
\left({ }^{\circ} \mathrm{N}\right)\end{array}$ & $27-28$ Jan & 24-25 Mar & 21-22 Apr \\
\hline 30.25 & 76 & 72 & 65 \\
29.75 & 81 & 60 & 54 \\
29.25 & 83 & 49 & 47 \\
28.75 & 75 & 63 & 78 \\
28.25 & 72 & 74 & 88 \\
27.75 & 92 & 60 & 83 \\
27.25 & 100 & 53 & 77 \\
26.75 & 80 & 61 & 77 \\
26.25 & 65 & 65 & 74 \\
\hline
\end{tabular}




\section{The mixed-layer heat balance during FASINEX}

\section{a. Least-squares fits}

Our first step is to quantify the degree to which the terms of (4) are in balance at large scales by performing a least-squares fit of data to the terms. We consider the matrix problem

$$
\mathbf{G m}=\mathbf{d}+\mathbf{e},
$$

where $\mathbf{G}$ is the data kernel matrix, $\mathbf{m}$ is the model parameter vector, $\mathbf{d}$ is the data vector, and $\mathbf{e}$ is the residual error vector. The system (7) can be solved for $\mathbf{m}$ using inverse methods (Lawson and Hanson 1974; Fiadeiro and Veronis 1984; Hogg 1987; and Menke 1984). If the model is overdetermined, the solution that minimizes the mean-square-error $|\mathbf{e}|^{2}$ (the least-squares solution ) is normally sought.

Given multiple realizations of (4), we can derive a matrix problem of the form (7). The $j$ th realization of (4) can be written in the form

$$
\begin{aligned}
& m_{1}\left\{-\frac{c}{f} \mathbf{k} \cdot\left(\nabla T_{s} \times \vec{\tau}\right)\right\}_{j} \\
& \quad+m_{2}\left\{-c \frac{h}{H}\left[\frac{1}{\beta} \mathbf{k} \cdot(\nabla \times \vec{\tau})+\frac{1}{f} \tau^{(x)}\right] T_{s y}\right\}_{j} \\
& +m_{3}\left\{\rho_{0} \operatorname{chk} \nabla^{2} T_{s}\right\}_{j}+m_{4}=\left\{\rho_{0} c h T_{s l}\right\}_{j}+e_{j},
\end{aligned}
$$

where $m_{1}, m_{2}, m_{3}$, and $m_{4}$ are the elements of $\mathbf{m}$, the expressions in braces on the left side are the elements from the first three columns in the $j$ th row of $\mathbf{G}$, the expression in braces on the right side is the $j$ th element of $\mathbf{d}$, and $e_{j}$ is the $j$ th element of e. We have used the model parameter $m_{4}$ to represent $Q_{R}$. All expressions in braces can be calculated using smoothed 5-day $T_{s}$ maps along with 5-day FNOC wind stress and windstress curl maps interpolated to the $T_{s}$ grid using bicubic splines, then averaged over a specified time interval if desired. A separate realization $j$ of $(8)$ can thus be obtained at each $T_{s}$ grid point. To reduce computation time, we only used the realizations at every other point $\left(0.5^{\circ}\right.$ resolution $)$, from point $(2,2)$ in the southwest to $(44,38)$ in the northeast, to perform our solutions. We used seven different temporal averaging intervals: the 4-month interval along with the same six 25-day intervals analyzed in Part I. The first five 25-day intervals coincide with the 4-month interval.

The parameters $h=71.3 \mathrm{~m}$ (Table 2), $H=1000$ $\mathrm{m}$, and $k=1000 \mathrm{~m}^{2} \mathrm{~s}^{-1}$ were used to calculate the expressions within braces in (8), except for the sixth 25 -day time interval when $h=25 \mathrm{~m}$ (estimated from another ship-of-opportunity cross section run during 27-28 May) was used to reflect the formation of the shallow seasonal thermocline. With this selection of parameters, the expressions within braces are expected to be the same order of magnitude, giving all terms approximately equal weight in the least-squares solu- tions. The selected value of $k$ is also the correct order of magnitude to account for the poleward heat flux in the mixed layer due to mesoscale eddies in the western North Atlantic estimated by Voorhis et al. (1976). In the solutions, the model parameter $m_{4}$ will essentially extract a spatially averaged rate of change in heat content over the entire analysis domain that is not accounted for by the other terms on the left side of (8). We therefore expect it to represent most of the heat content variability due to the annual cycle, which is dominated by space scales much larger than the analysis domain. The contributions at large scales of all other processes not explicitly modeled will appear in the residual error term of $(8)$.

We constrain the model parameters $m_{1}, m_{2}$, and $m_{3}$ to be positive in the least-squares solutions using algorithms presented in Lawson and Hanson (1974). We calculate the expected errors for the components of the model parameter vector using

$$
\mathbf{f}^{2} \mathbf{I}=\frac{|\mathbf{e}|^{2}}{N_{d}}\left(\mathbf{G}^{\mathrm{T}} \mathbf{G}\right)^{-1} \mathbf{l},
$$

where $\mathbf{f}^{2}$ is the square of the expected error vector of $\mathbf{m}, \mathbf{I}$ is the identity matrix, and $N_{d}$ is the number of degrees of freedom (the number of statistically independent realizations minus the number of model parameters) (Hogg 1987). Since the terms typically had spatial correlation scales of $200-250 \mathrm{~km}$, we had only about 15-25 independent realizations of (8). We therefore calculated $\mathrm{f}$ assuming that $N_{d}=16$ for all 7 solutions. From a singular value decompositions of $\mathbf{G}$, we found that all solutions were adequately determined (the model was not ill-conditioned).

\section{b. Properties of the least-squares solutions}

The Ekman and interior advection terms did not contribute significantly to the heat balance in any of the seven solutions because the estimates of $m_{1}$ and $m_{2}$ were always smaller than their expected errors. The diffusion term only contributed significantly to the balance during the final 25-day interval. In contrast, the term $m_{4}$ contributed significantly to all seven solutions, apparently extracting most of the influence of the annual cycle as expected. The model parameter $m_{4}$ equalled $-34.9 \mathrm{~W} \mathrm{~m}^{-2}$ for the first 25-day interval and $-77.3 \mathrm{~W} \mathrm{~m}^{-2}$ for the second (Table 3 ). It was positive for the remaining four 25-day intervals, equalling 19.5 , $66.5,52.4$, and $88.4 \mathrm{~W} \mathrm{~m}^{-2}$, respectively. It was much smaller in the 4-month solution $\left(4.8 \mathrm{~W} \mathrm{~m}^{-2}\right)$ since the net influence of the annual cycle was very small over this time interval.

To determine why the advection and diffusion terms are insignificant in the solutions, we will describe the properties of the heat balance during the 4-month interval. Terms of (4), calculated using the selected values of $h, H$, and $k$ and averaged over the 4-month interval, are contoured in Fig. 2. The insignificant spatial (pat- 
TABLE 3. Summary of the seven least-squares solutions of (8) for the 4-month and the six 25-day time intervals. Because of the insignificance of other terms (see text), only the properties of the solutions of $m_{4}$ are summarized here.

\begin{tabular}{lcc}
\hline Time interval & $\begin{array}{c}\text { Estimate of } m_{4} \\
\left(\mathrm{~W} \mathrm{~m}^{-2}\right)\end{array}$ & $\begin{array}{r}\text { Expected } \\
\text { error of } m_{4} \\
\left(\mathrm{~W} \mathrm{~m}^{-2}\right)\end{array}$ \\
\hline 11-15 Jan to 11-15 May & 4.8 & 1.1 \\
11-15 Jan to 31 Jan-4 Feb & -34.9 & 3.1 \\
5-9 Feb to 25 Feb-1 Mar & -77.3 & 3.6 \\
2-6 Mar to 22-26 Mar & 19.5 & 2.7 \\
27-31 Mar to 16-20 Apr & 66.5 & 2.0 \\
21-25 Apr to 11-15 May & 52.4 & 4.6 \\
16-20 May to 5-9 Jun & 88.4 & 2.9 \\
\hline
\end{tabular}

tern) correlations among them (Table 4) are visually evident in Fig. 2. The time derivative term, which is proportional to the total change in heat content per unit area during the 4-month interval, has a distinct anisotropic banded structure with the major axis oriented SW-NE (Fig. 2). These bands have a horizontal peak-to-peak scale in the minor axis direction of several hundred kilometers, and the rates of change of heat content in the bands range between -30 and $+45 \mathrm{~W}$ $\mathrm{m}^{-2}$, with an rms amplitude of $14.4 \mathrm{~W} \mathrm{~m}^{-2}$ (Table $5)$. By choosing a time interval when the net influence of the annual cycle was very small, we successfully isolated large-scale variability in the temporal change of mixed-layer heat content in the FASINEX region.

The other terms of (4) cannot account for this observed change in heat content during the 4-month interval. The Ekman advection term acts to decrease $T_{s}$ in the northern part of the domain and increase it in the southern part (Fig. 2) as expected within the STCZ, with the transition occurring at $25^{\circ}-26^{\circ} \mathrm{N}$ (at $28^{\circ}-$ $29^{\circ} \mathrm{N}$ ) near the western (eastern) end of the domain. The interior advection term tends to produce cooling throughout nearly the entire analysis domain due to the existence of mean negative $\mathbf{k} \cdot(\nabla \times \vec{\tau})$ and the southward advection that it drives. The structure of the horizontal diffusion term simply reflects its proportionality to $\nabla^{2} T_{s}$. Also, given the estimates of $h, H$, and $k$ that we used, these terms are all substantially

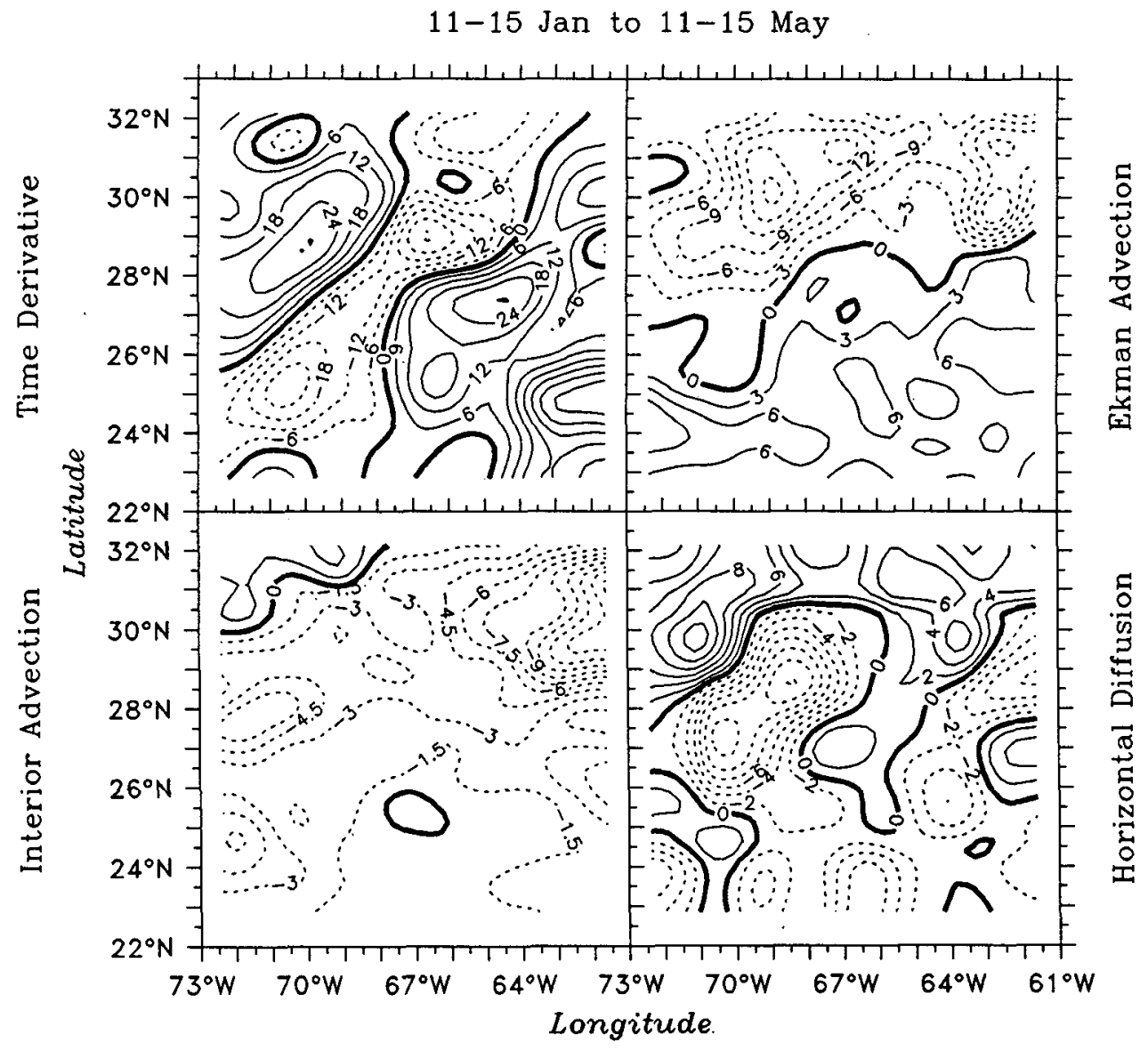

FIG. 2. Contour plots of four terms of (4) in units of $\mathrm{W} \mathrm{m}^{-2}$, averaged over the time interval 11-15 January through 11-15 May 1986. Dashed contours indicate negative values, signifying decreasing heat content per unit area with time. 
TABLE 4. Matrix of pattern correlation coefficients among the terms of (4) and the residual error of the least-squares solution of (8), all averaged over the 4-month time interval. Assuming that the coefficients are estimated with about 20 effective degrees of freedom based on zonal and meridional correlation scales, we assume that values $\geqslant 0.43$ are significant to $95 \%$ confidence.

\begin{tabular}{lrcrc}
\hline & \multicolumn{4}{c}{ Term } \\
\cline { 2 - 5 } \multicolumn{1}{c}{ Term } & $\begin{array}{c}\text { Time } \\
\text { derivative }\end{array}$ & $\begin{array}{c}\text { Ekman } \\
\text { advection }\end{array}$ & $\begin{array}{c}\text { Interior } \\
\text { advection }\end{array}$ & $\begin{array}{c}\text { Horizontal } \\
\text { diffusion }\end{array}$ \\
\hline Time derivative & & & & \\
Ekman advection & -0.04 & & & \\
Interior advection & 0.18 & 0.39 & & \\
Horizontal diffusion & -0.09 & -0.35 & 0.09 & \\
Residual error & 0.85 & -0.13 & -0.24 & -0.23 \\
\hline
\end{tabular}

smaller in magnitude than the observed rate of heat content change. The spatial rms amplitude of the time derivative term is more than twice as great as that of the Ekman advection term, nearly five times as great as that of the interior advection term, and about three times as great as that of the diffusion term (Table 5). Since only the constant term $m_{4}$ is significant in the 4month solution of (8), the residual error field of that solution (not shown) essentially equals the time derivative term with the mean removed. The pattern correlation between this residual error field and the time derivative term is 0.85 (Table 4 ).

Other physical processes must have been responsible for the changes in heat content observed during the 4month interval. Halliwell and Cornillon (1989, henceforth referred to as $\mathrm{HC}$ ) identified and described largescale anisotropic spatial anomaly features present in the $T_{s}$ field. The major axes of these features were oriented SW-NE, and they propagated in a predominantly westward direction. It is demonstrated in $\mathrm{HC}$ that the propagation of these features was largely responsible for the observed banded structure in the rate of change of heat content during the 4-month interval. It follows that the physical processes responsible for the existence of these features, which were not explicitly included in our heat balance model, may have contributed to our inability to detect the contribution of wind-driven horizontal heat advection to this balance. Analyses presented in HC and in Halliwell (1989) suggested, but did not prove conclusively, that these features could be driven by the underlying internal eddy field.

We have attempted to detect a balance at large horizontal scales among the temporal rate of change of mixed-layer heat content, wind-driven horizontal heat advection, and decay processes represented by a horizontal diffusion term during FASINEX. This simple balance could not explain the observed large-scale variability in mixed-layer heat content. The strong influence of other processes, which could not be directly estimated with available data, made this balance impossible to detect, even during the 4-month time in- terval when the influence of the annual cycle was essentially averaged out. The inability to detect a relationship between Ekman advection and the temporal change in the upper-ocean heat content is somewhat surprising because such a relationship was detected in the Pacific Ocean by Roden and Paskausky (1978). Such a relationship could still exist in the FASINEX region, since the relatively strong influence of the propagating anomaly features may have simply prevented us from statistically detecting it. However, we cannot determine whether the influence of the interior advection term is undetectable because it is masked by the influence of the propagating anomaly features or because the Sverdrup balance simply does not hold in the FASINEX region. Similarly, we cannot determine whether the horizontal diffusion term poorly represents the decay processes that are undoubtedly present. There are many reasons to suspect that the diffusion term used here will poorly represent decay processes. For example, even if horizontal diffusion is a significant decay process, the assumption of a constant diffusion coefficient $k$ is questionable in the vicinity of the SFZ, even though the analysis domain is sufficiently far from the Gulf Stream for the eddy energy to be approximately independent of position within most of the domain (Dantzler 1977; Emery 1983; Robinson et al. 1983).

\section{Variability of the SFZ during FASINEX}

Although the results of the heat balance analysis were disappointing, it is still of interest to search for a response of the SFZ to Ekman advection. To perform this analysis, we calculate terms of the frontogenesis equation (6), and also calculate the field of $\left|\nabla T_{s}\right|^{2} / 2$, then average these fields over the 4-month interval. The location of the mean SFZ is illustrated in the contour plot of $\left|\nabla T_{s}\right|^{2} / 2$ (Fig. 3). From the time derivative term (Fig. 3), it is evident that west of about $65^{\circ} \mathrm{W},\left|\nabla T_{s}\right|^{2} / 2$ increases (decreases) with time to the north (south) of the central latitude of the SFZ. This pattern results from the northward shift of the SFZ that occurred in this region during the 4-month interval (Part I). Also, a band where relatively strong fronto-

TABLE 5. Means and spatial rms amplitudes of the terms of (4) contoured in Fig. 2 along with the residual error of the 4-month solution of (8), and meridional rms amplitudes of the zonally-averaged terms of (4) plotted in Fig. 7.

\begin{tabular}{lccc}
\hline \hline \multicolumn{1}{c}{ Term } & $\begin{array}{c}\text { Mean } \\
\left(\mathrm{W} \mathrm{m}^{-2}\right)\end{array}$ & $\begin{array}{c}\text { Rms } \\
\text { amplitude } \\
\left(\mathrm{W} \mathrm{m}^{-2}\right)\end{array}$ & $\begin{array}{c}\text { Rms amplitude of } \\
\text { zonally averaged } \\
\text { term }\left(\mathrm{W} \mathrm{m}^{-2}\right)\end{array}$ \\
\hline Time derivative & 5.0 & 14.4 & 3.4 \\
Ekman advection & -1.2 & 6.8 & 1.9 \\
Interior advection & -3.1 & 2.9 & \\
Horizontal diffusion & -0.4 & 4.8 & \\
Residual error & 0.0 & 16.6 & \\
\hline
\end{tabular}




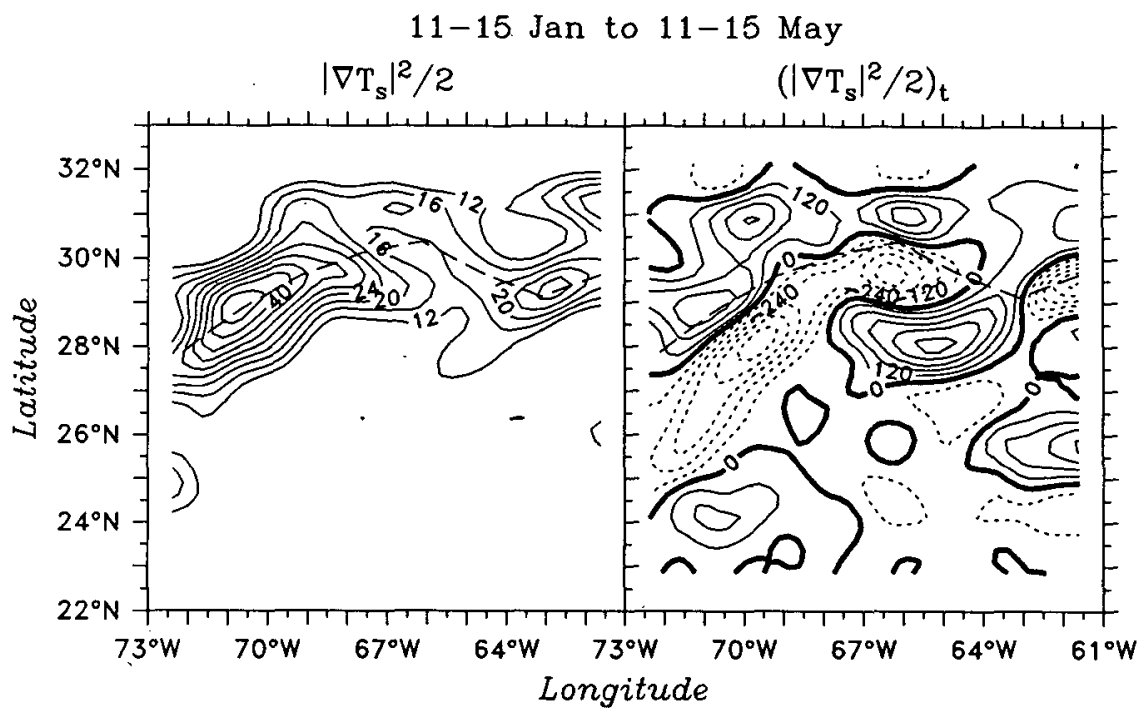

FlG. 3. Contour plots of $\left|\nabla T_{s}\right|^{2} / 2$ in ${ }^{\circ} \mathrm{C}^{2} \mathrm{~m}^{-2}$ (multiplied by $10^{12}$ ) and $\left(\left|\nabla T_{s}\right|^{2} / 2\right)$ in ${ }^{\circ} \mathrm{C}^{2}$ $\mathrm{m}^{-2} \mathrm{~s}^{-1}$ (multiplied by $10^{20}$ ), both averaged over the 4-month time interval. Negative values (dashed contours) in the right panel indicate that frontolysis occurred on average. The mean latitude of the SFZ is traced by the dashed line. The path of the SFZ is split in two near $67^{\circ} \mathrm{W}$ (left panel), so the mean path that we show is located between these two paths at this longitude.

genesis occurred on average exists near $29^{\circ} \mathrm{N}$ between $63^{\circ}$ and $67.5^{\circ} \mathrm{W}$, a pattern that probably represents the effects of a relatively strong segment of the SFZ centered near $63^{\circ} \mathrm{W}$ in mid-January that shifted westward to about $66.5^{\circ} \mathrm{W}$ by the beginning of May (Part I). The Ekman advection term (Fig. 4) cannot account for this observed SFZ variability. West of $67^{\circ} \mathrm{W}$, Ekman advection contributes to frontogenesis (fronto-

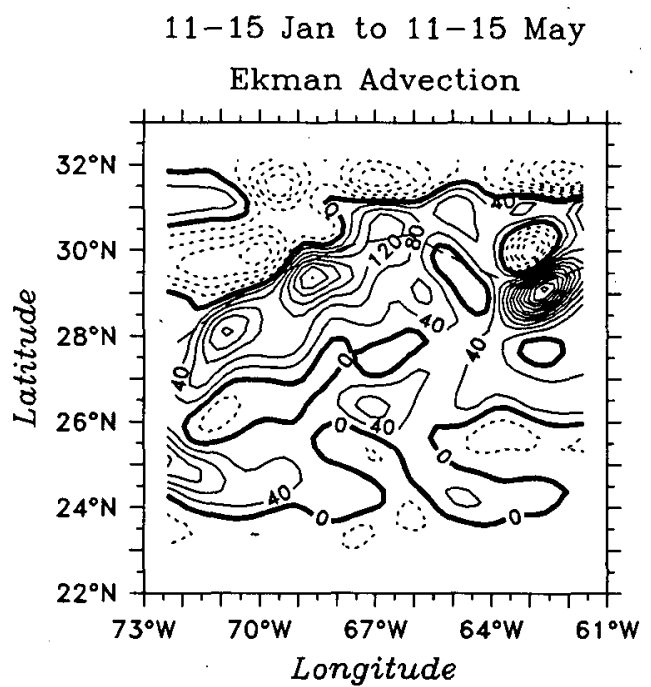

FIG. 4. Contour plot of the Ekman advection term from (6) in ${ }^{\circ} \mathrm{C}^{2} \mathrm{~m}^{-2} \mathrm{~s}^{-1}$, multiplied by $10^{20}$ and averaged over the 4 -month time interval. Negative values (dashed contours) indicate that the term contributed to frontolysis. The mean latitude of the SFZ is traced by the dashed line. lysis) to the south (north) of the mean SFZ, and is consequently acting to shift the SFZ to the south in a region where it actually shifted northward. The strong frontogenesis observed near $29^{\circ} \mathrm{N}$ between $63^{\circ} \mathrm{W}$ and $67.5^{\circ} \mathrm{W}$ (Fig. 3 ) is also not driven by the Ekman advection term.

The temporal evolution of the $T_{s}$ gradient caused by Ekman advection in (5) can be divided into two components as follows:

$$
\begin{aligned}
\nabla\left[\mathbf{k} \cdot\left(\nabla T_{s} \times \vec{\tau}\right)\right]= & \left(T_{s x} \nabla \tau^{(y)}-T_{s y} \nabla \tau^{(x)}\right) \\
& +\left(\tau^{(y)} \nabla T_{s x}-\tau^{(x)} \nabla T_{s y}\right) .
\end{aligned}
$$

The terms in the first set of parentheses on the right side of $(10)$ represent the local convergence of isotherms caused by spatial gradients in the $\vec{\tau}$ field (isotherm convergence component), while the terms in the second set of parentheses represent the local winddriven advection of the existing isotherm field (isotherm advection component). The separate contribution of each component to frontogenesis is calculated by taking the dot product between $\nabla T_{s}$ and (10) (Fig. $5)$. The isotherm advection component is acting to shift the SFZ southward at all longitudes (except near $64^{\circ}-66^{\circ} \mathrm{W}$ where the SFZ in weak) due to the mean eastward wind stress existing in that latitude belt (Fig. 6 , Part 1 ). Assuming that $h=71.3 \mathrm{~m}$, Ekman advection acts to shift the SFZ southward at about $0.4 \mathrm{~km}_{\text {day }}{ }^{-1}$ during a period when it actually shifts northward at 2$3 \mathrm{~km}$ day $^{-1}$ near the western edge of the domain (Fig. 15, Part I). The isotherm convergence component contributes to frontogenesis at the latitude of the mean 


$$
\text { 11-15 Jan to 11-15 May }
$$

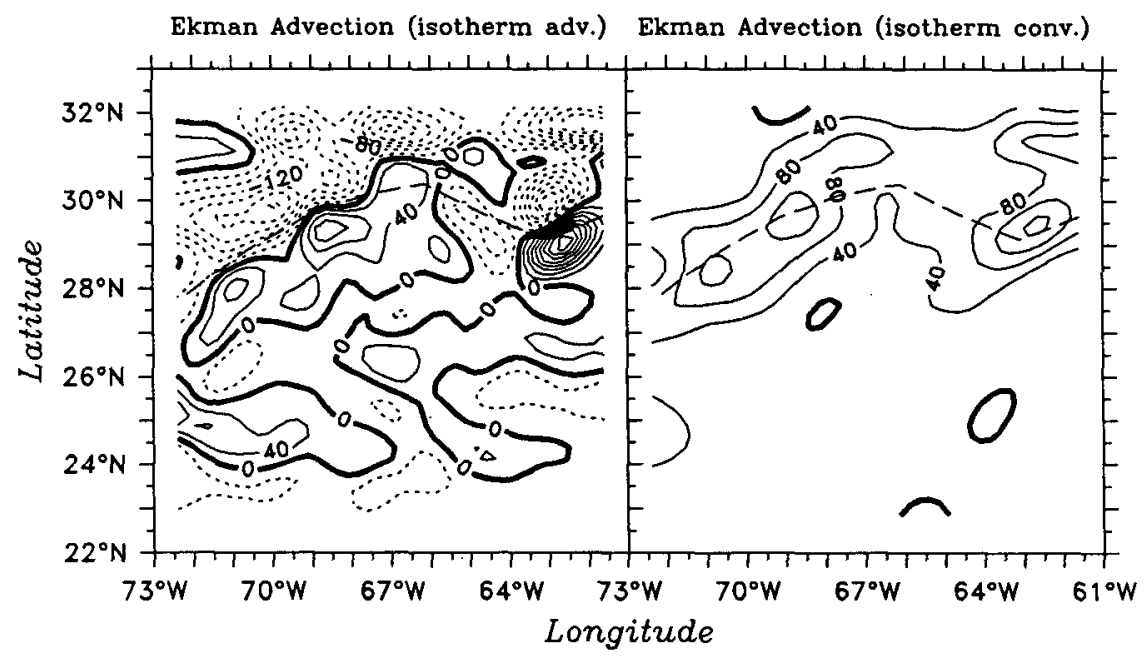

FIG. 5. Contour plots of the isotherm advection and isotherm convergence components of the Ekman advection term from (6) in ${ }^{\circ} \mathrm{C}^{2} \mathrm{~m}^{-2} \mathrm{~s}^{-1}$, multiplied by $10^{20}$ and averaged over the 4 month time interval. Negative values (dashed contours) indicate that the term contributed to frontolysis. The mean latitude of the SFZ is traced by the dashed line.

SFZ across the entire analysis domain (Fig. 5), increasing $\left|\nabla T_{s}\right|^{2} / 2$ at the rate of about $1.2 \times 10^{-13}{ }^{\circ} \mathrm{C}^{2}$ $\mathrm{m}^{-2}$ per day in the western half of the domain where the observed value for $\left|\nabla T_{s}\right|^{2} / 2$ is as large as 4.5

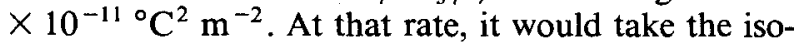
therm convergence component nearly 200 days to increase $\left|\nabla T_{s}\right|^{2} / 2$ from $2.5 \times 10^{-11}$ to $5 \times 10^{-11}$ ${ }^{\circ} \mathrm{C}^{2} \mathrm{~m}^{-2}$.

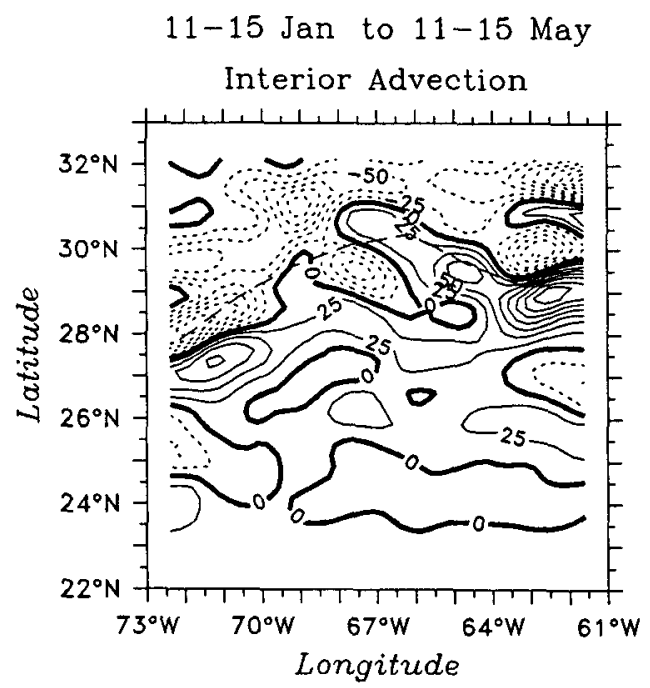

FIG. 6. Contour plot of the interior advection term from (6) in ${ }^{\circ} \mathrm{C}^{2} \mathrm{~m}^{-2} \mathrm{~s}^{-1}$, multiplied by $10^{20}$ and averaged over the 4-month time interval. Negative values (dashed contours) indicate that the term contributed to frontolysis. The mean latitude of the SFZ is traced by the dashed line.
Although we are probably underestimating this rate of frontogenesis because FNOC fields have an effective smoothing scale of several hundred kilometers, Ekman advection affects $T_{s}$ gradients too slowly to account for most of the SFZ variability actually observed. It is still possible that Ekman advection acts to generate and maintain the SFZ over long time scales, but that this response is masked by larger-amplitude, shorter-period variability generated by other processes. It is going to be difficult to quantify to what extent Ekman convergence is responsible for the existence of the SFZ, at least in the FASINEX region.

The interior advection term tends to produce frontogenesis (frontolysis) to the south (north) of the mean SFZ variability observed within the analysis domain the SFZ southward as expected due to the existence of mean negative wind stress curl (Fig. 8, Part I). However, this southward shift is only about $0.1 \mathrm{~km}^{\mathrm{day}}{ }^{-1}$. Even if the simple Sverdrup balance does hold in our domain, it does not appear to have much influence on the SFZ. The horizontal diffusion term (not shown), if acting alone, would simply produce frontolysis within the SFZ as expected.

\section{The zonally averaged $T_{s}$ balance \\ a. The 4-month averaged balance}

Since the westward-propagating $T_{s}$ spatial anomaly features strongly influenced the heat balance at large horizontal scales during the 4-month interval, it is conceivable that the influence of Ekman advection on $T_{s}$ and the SFZ could be detected if the influence of the propagating features was averaged out. We therefore 
zonally averaged the 4-month averaged time derivative and Ekman advection terms of (4) at each latitude across the entire analysis domain, then graphed them as a function of latitude in Fig. 7 along with zonallyaveraged $T_{s}$, removing the meridional means and meridional trends from each of these functions to focus on large-scale variability.

Zonally averaged $T_{s}$, with the negative mean meridional trend removed (Fig. 7), decreases toward the north between $28.5^{\circ}$ and $30.5^{\circ} \mathrm{N}$, so we consider this to be the latitude band within which the zonally-averaged SFZ is confined. The largest negative gradient exists at $29.4^{\circ} \mathrm{N}$, so we consider this to be the mean latitude of the zonally averaged SFZ during the 4month interval. Some similarity is observed between the meridional structures of the $T_{s}$ function and the time-derivative term (Fig. 7). The zonally-averaged upper ocean heat content increased with time during the 4-month interval between about $25.25^{\circ}$ and $28.75^{\circ} \mathrm{N}$, and decreased with time to the north and south of this band. Relatively strong zonally-averaged frontogenesis therefore occurred between about $28^{\circ}$ and $29^{\circ} \mathrm{N}$, centered about $1^{\circ}$ of latitude to the south of the central latitude of the zonally averaged SFZ. The central latitude of the SFZ thus tended to shift southward with time during the 4-month interval, an observation that will be confirmed in section $6 \mathrm{~b}$.

Some similarity is also observed between the meridional structures of the time-derivative and Ekman advection terms (Fig. 7). In particular, Ekman advection is contributing to frontogenesis on average between about $28^{\circ}$ and $29.5^{\circ} \mathrm{N}$, nearly the same latitude band where zonally averaged frontogenesis is actually observed. However, the similarities between these two terms do not prove that a relationship exists because they could have occurred by chance. Some differences

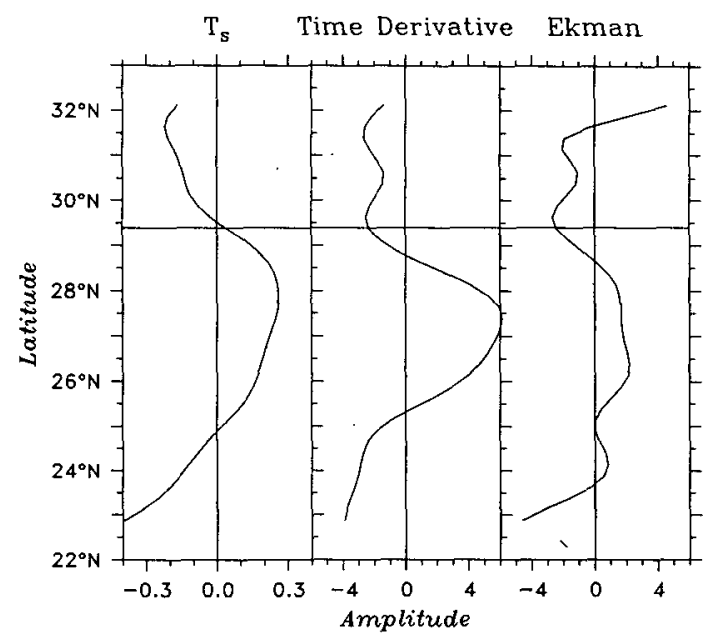

FIG. 7. Zonal averages of $T_{s}$, along with the time derivative and Ekman advection terms of (4), averaged over the 4-month time interval. The mean values and meridional trends have been removed from these functions. are also observed between the terms. The Ekman advection term substantially underestimates the observed rate of zonally averaged warming that occurs near $27^{\circ}-$ $28^{\circ} \mathrm{N}$, and hence underestimates the rate of frontogenesis that occurs just to the north. The meridional rms amplitudes of the time-derivative and Ekman terms, 3.35 and $1.90 \mathrm{~W} \mathrm{~m}^{-2}$, respectively (Table 5 ), differ substantially. These differences may exist because we have not completely averaged out the influence of the propagating anomaly features, because the assumption of constant $h$ distorts our estimate of the Ekman term, or because the estimate of $h$ used was too large. We consider these results encouraging, but we have still fallen short of proving whether Ekman advection is primarily responsible for the existence of the SFZ, or of quantifying its influence on it.

\section{b. Temporal variability of forcing by Ekman advection}

To describe the temporal variability of these zonally averaged terms, terms averaged over the six 25 -day intervals were zonally averaged, then contoured as a function of time and latitude in Fig. 8. For comparison, we zonally averaged 25-day maps of $T_{s}$ and contoured this as a function of time and latitude in Fig. 8. The meridional means and meridional trends have been removed from these functions within each 25-day interval.

The zonally averaged $T_{s}$ function maintains a similar meridional distribution throughout the entire time interval, tending to increase in amplitude with time. A strengthening and southward shift with time of the zonally-averaged SFZ is visually evident. The meridional distribution of the time-derivative term has large temporal fluctuations while the Ekman advection term maintains a relatively consistent meridional distribution. This comparison illustrates the necessity of temporally averaging the terms over an interval substantially longer than one month to even marginally detect the influence of Ekman advection on the SFZ.

\section{Discussion}

We have attempted to quantify the influence of two components of wind-driven horizontal heat advection, that due to Ekman transport and that due to interior geostrophic (Sverdrup minus Ekman) meridional transport, on the observed variability of mixed-layer heat content and on the SFZ at large horizontal scales $[O(1000) \mathrm{km}$ wavelength] during FASINEX. Unfortunately, we succeeded primarily in documenting how difficult it is to detect this influence in the FASINEX region because other processes, whose effects we could not estimate with available data, exerted a much stronger influence. The largest changes in the mixed-layer heat content, which can be up to an order of magnitude larger than what can be accounted for by wind-driven horizontal heat advection, are driven by the annual cycle of vertical heat flux. Even when we tried to detect 


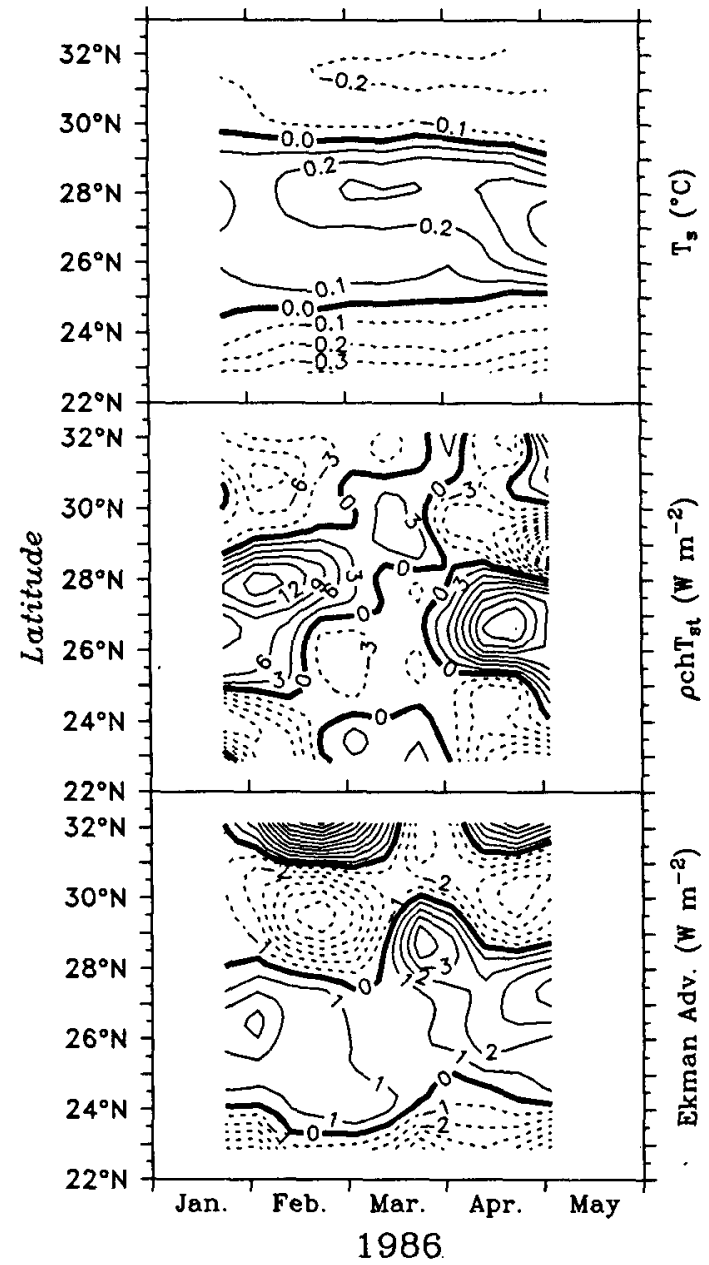

FIG. 8. Temporal variability of zonal averages of $T_{s}$ in ${ }^{\circ} \mathrm{C}$ (left), and also of the time derivative (center) and Ekman advection (right) terms of (4) in $\mathrm{W} \mathrm{m}^{-2}$, contoured as a function of latitude and time. These functions were calculated for the first five 25-day intervals used in the least-squares solutions (Table 1). The mean values and meridional trends at each time have been removed from these functions.

the average influence of wind-driven advection over the 4-month time interval between mid-January and mid-May, during which the net temperature change due to the annual cycle was very small, westwardpropagating $T_{s}$ spatial anomaly features with scales of several hundred kilometers ( $\mathrm{HC}$ ) apparently had the dominant influence on the mixed-layer heat content. Local wind-driven horizontal heat advection was not responsible for the existence of these propagating features, and they may be related to the underlying internal eddy field (HC; Halliwell 1989). Neither winddriven advection mechanism could account for the SFZ variability observed within the analysis domain during this 4-month interval. For example, in the western part of the domain, the SFZ shifted northward while Ekman advection was acting to shift it southward.
This inability to detect the responses of both mixedlayer heat content and the SFZ to wind-driven horizontal heat advection in the Ekman layer was puzzling because some success had been achieved in the North Pacific Ocean (Roden 1980; Roden and Paskausky 1978 ). Since the large influence of the westward-propagating $T_{s}$ anomaly features dominated the observed changes in heat content during the 4-month interval, we decided to zonally average the terms from the heat balance equation in an attempt to average out the influence of these features. For terms averaged over the 4-month interval, the zonally averaged time derivative and Ekman advection terms had qualitatively similar meridional distributions, suggesting (but not proving conclusively) that the zonally averaged mixed-layer heat content could be changing with time partly in response to the zonally averaged heat advection in the Ekman layer. The zonally averaged SFZ was observed to shift southward during the 4-month interval, and this shift could be partly accounted for by Ekman advection. However, the observed rate of change of zonally averaged heat content was about $75 \%$ larger than the rate accounted for by Ekman advection, which could indicate that the influence of the propagating anomaly features was not averaged out, the assumption of constant mixed-layer thickness $h$ was in error, or the estimate of $h$ used was too large. It is possible that at large scales, Ekman advection contributes signifcantly to the mixed-layer heat balance and acts to maintain the SFZ at periods $\geqslant 3-4$ months in the FASINEX region, but further studies will need to be undertaken to verify that this is true and to quantify its importance for generating and maintaining the SFZ in this region.

Acknowledgments. This research was performed with the support of the Office of Naval Research (No. N00014-87-KT0235) as part of FASINEX. All figures were generated using the interactive graphics package PLOT5, developed by Dr. Donald Denbo. Dr. Ken Brink and two anonymous reviewers provided helpful comments and suggestions on an early version of the manuscript.

\section{REFERENCES}

Böhm, E., 1988: Subtropical fronts in the Sargasso Sea: a four-year satellite analysis. M.S. Thesis, Graduate School of Oceanography, University of Rhode Island, Narragansett, RI, $61 \mathrm{pp}$.

Brink, K. H., 1988: Evidence for wind-driven current fluctuations in the western North Atlantic. J. Geophys. Res., 94, 2029-2044.

Cushman-Roisin, B., 1981: Effects of horizontal advection on upper ocean mixing-a case of frontogenesis. J. Phys. Oceanogr., 11, 1345-1356.

- 1984: On the maintenance of the subtropical front and its associated countercurrent. J. Phys. Oceanogr., 14, 1179-1190.

Dantzler, H. L., Jr., 1977: Potential energy maxima in the tropical and subtropical North Atlantic. J. Phys. Oceanogr., 7, 512-519.

deRuijter, W. P. M., 1983a: Frontogenesis in an advective mixedlayer model. J. Phys. Oceanogr., 13, 487-495. 
$\ldots, 1983 \mathrm{~b}$ : Effects of velocity shear in advective mixed-layer models. J. Phys. Oceanogr., 13, 1589-1599.

deSzoeke, R. A., 1980: On the effects of horizontal variability of wind stress on the dynamics of the ocean mixed layer. J. Phys. Oceanogr., 10, 1439-1454.

Emery, W. J., 1983: On the geographical variability of the upper level mean and eddy fields in the North Atlantic and North Pacific. J. Phys. Oceanogr., 13, 269-291.

Evans, D. L., G. A. Strout and A. K. Monaghan, 1986: FASINEX ship-of-opportunity data report. Tech. Rep. Ref. No. 86-6, Graduate School of Oceanography, University of Rhode Island, Narragansett, Rhode Island.

Fiadeiro, M. E., and G. Veronis, 1984: Obtaining velocities from tracer distributions. J. Phys. Oceanogr., 14, 1734-1746.

Halliwell, Jr., G. R., 1990: Ship-of-opportunity XBT cross-sections of the western North Atlantic subtropical convergence zone. $J$. Geophys. Res., in press.

- and P. Cornillon, 1990: Large-scale SST variability in the western North Atlantic subtropical convergence zone during FASINEX. Part I: Description of SST and wind stress fields. $J$. Phys. Oceanogr., 20, 209-222.

$\longrightarrow$, and —, 1989: Large-scale SST anomalies associated with subtropical fronts in the western North Atlantic during FASINEX. J. Mar. Res., in press.

Haney, R. L., 1971: Surface thermal boundary condition for ocean circulation models. J. Phys. Oceanogr., 1, 241-248.

Hogg, N. G., 1987: A least-squares fit of the advective-diffusive equations to Levitus Atlas data. Deep-Sea Res., 45, 347-375.

Lawson, C. L., and R. J. Hanson, 1974: Solving Least Squares Problems. Prentice Hall, 340 pp.

Menke, W., 1984: Geophysical Data Analysis: Discrete Inverse Theory. Academic Press, 260 pp.

Niiler, P. P., and C. J. Koblinsky, 1985: A local time-dependent Sverdrup balance in the eastern North Pacific Ocean. Science, 229, 754-756.

Paduan, J., and R. deSzoeke, 1986: Heat and energy balances in the upper ocean at $50^{\circ} \mathrm{N}, 140^{\circ} \mathrm{W}$ during November 1980 (STREX). J. Phys. Oceanogr., 16, 25-38.

Pennington, N. J., R. A. Weller and K. H. Brink, 1988: FASINEX moored current meter array data report. WHOI Tech. Rep. 8863, Woods Hole Oceanographic Institution, Woods Hole, MA.

Pollard, R., 1986: Frontal surveys with a towed profiling conductivity/ temperature/depth measurement package (SeaSoar). Nature, $323,433-435$.
Robinson, A. R., N. E. Huang, C. D. Leitao and C. G. Parra, 1983: A study of the variability of ocean currents in the northwestern Atlantic using satellite altimetry. J. Phys. Oceanogr., 13, 565585.

Roden, G. I., 1975: On North Pacific temperature, salinity, sound velocity, and density fronts and their relation to the wind and energy flux fields. J. Phys. Oceanogr., 5, 557-571.

$\ldots$, 1980: On the variability of surface temperature fronts in the western Pacific, as detected by satellite. J. Geophys. Res., 85, 2704-2710.

_ 1981: Mesoscale thermohaline, sound velocity, and baroclinic flow structure of the Pacific subtropical front during the winter of 1980. J. Phys. Oceanogr., 11, 658-675.

_ and frontolysis in the North Pacific Ocean using satellite and surface meteorological data from January 1977. J. Geophys. Res., 83, 4545-4550.

Roemmich, D., and C. Wunsch, 1985: Two transatlantic sections: meridional circulation and heat flux in the subtropical North Atlantic Ocean. Deep-Sea Res., 32, 619-664.

Stage, S. A., and R. A. Weller, 1985: The Frontal Air-Sea Interaction Experiment (FASINEX); Part I: Background and scientific objectives. Bull. Amer. Meteor. Soc., 66, 1511-1520.

- - , and _ 1986: The Frontal Air-Sea Interaction Experiment (FASINEX); Part II: Experimental plan. Bull. Amer. Meteor. Soc., 67, 16-20.

Sverdrup, H. U., 1947: Wind-driven currents in a baroclinic ocean; with application to the equatorial currents of the eastern Pacific. Proc. Natl. Acad. Sci., 33, 3-10.

Takeuchi, K., 1984: Numerical study of the subtropical front and the subtropical countercurrent. J. Oceanogr. Soc. Japan, 40, 371-381.

Voorhis, A. D., 1969: The horizontal extent and persistence of thermal fronts in the Sargasso Sea. Deep-Sea Res., 16(Suppl.), 331-337.

ogenesis in the subtropical convergence of the western North Atlantic. J. Mar. Res., 40(Suppl.), 801-821.

- E. H. Schroeder and A. Leetmaa, 1976: The influence of deep mesoscale eddies on surface temperature in the North Atlantic subtropical convergence. J. Phys. Oceanogr., 6, 953-961.

Welander, P., 1981: Mixed layers and fronts in simple ocean circulation models. J. Phys. Oceanogr., 11, 148-152.

Wunsch, C., and D. Roemmich, 1985: Is the North Atlantic in Sverdrup balance? J. Phys. Oceanogr., 15, 1876-1880. 